\title{
Valbenazine for the Treatment of Adults with Tardive Dyskinesia
}

\author{
Harshit Gupta, BSA', Alycee R. Moity, BS², Allison Jumonville, BS², Sarah Kaufman, MS², Amber N. Edinoff, MD³ (0)
} Alan D. Kaye, MD, PhD ${ }^{4}$

1 David Geffen School of Medicine, University of California Los Angeles, 2 School of Medicine, Louisiana State University Health Shreveport, 3 Department of Psychiatry and Behavioral Medicine, Louisiana State University Health Shreveport, ${ }^{4}$ Department of Anesthesiology, Louisiana State University Health Shreveport

Keywords: dopamine, vmat2, antipsychotics, valbenazine, tardive dyskinesia

https://doi.org/10.52965/001c.24929

\section{Health Psychology Research}

Vol. 9, Issue 1, 2021

\section{Purpose of review}

This a comprehensive review of the literature regarding the use of Valbenazine in treating tardive dyskinesia. A primarily oral movement disorder induced by chronic exposure to certain classes of medications, tardive dyskinesia is often resistant to many therapeutic approaches. This review presents the background, evidence, and indications for the use of Valbenazine as a treatment option for this condition.

\section{Recent Findings}

Tardive dyskinesia is a disorder arising from long-term exposure to medications that blocked dopamine receptors, primarily antipsychotics. It is characterized by abnormal movements of the oral-buccal-lingual structures as well as associated pain and hypertrophy. Simply stopping the use of the dopamine blocking agents effectively alleviates the symptoms but is not always reliable hence the need for another therapeutic approach.

Valbenazine is thought to function as a highly selective inhibitor of the VMAT2 vesicular monoamine transporter resulting in decreased availability of dopamine in the presynaptic cleft. This leads to decreased dopaminergic activation of the striatal motor pathway. The FDA approved Valbenazine in 2017 to treat tardive dyskinesia in adults and needs to be evaluated with existing therapeutic approaches.

\section{Summary}

The chronic use of dopamine receptor blocking agents, most commonly antipsychotics, can lead to a movement disorder called tardive dyskinesia. Once symptom onset has occurred, these movement abnormalities can persist for years to permanently, depending on the speed and effectiveness of treatment. Valbenazine is a relatively newer option for the treatment of tardive dyskinesia in adults. Compared to other pharmaceutical agents, it is more selective and has limited toxicities making it an effective treatment regimen. However, further research, including additional direct comparison studies, should be conducted to fully evaluate this drug's usefulness.

\section{INTRODUCTION}

Medication-induced involuntary and repetitive movements can significantly toll the social, emotional, and physical well-being of patients. Specifically, tardive syndromes (TS) are movement disorders caused by chronic exposure to drugs, classified as dopamine receptor-blocking agents (DRBA), also known as neuroleptics. ${ }^{1}$ The differentiation of TS is often precise, and these syndromes can sometimes be

\footnotetext{
a Corresponding Author:

Dr. Amber Edinoff, MD

Louisiana State University Health Science Center Shreveport

Department of Psychiatry and Behavioral Medicine

1501 Kings Hwy

Shreveport, LA 71103

Phone: (318) 675-8969

Amber.edinoff@lsuhs.edu
} 
difficult to distinguish clinically. Tardive dyskinesia (TD) is a TS characterized by repetitive oral-buccal-lingual movements that include chewing, lip-smacking, pouting, opening, and closing the mouth. ${ }^{1,2}$ Patients may also report physical pain, difficulty swallowing, and even tongue hypertrophy. ${ }^{2}$ In addition to the physical symptoms experienced by patients, TD can also have a prominent effect on emotional and mental well-being. ${ }^{3}$ This is evident in a 2019 study that reported patients with TD typically have a significantly lower quality of life. The effect of TD on a patient's quality of life was further emphasized by data correlating more severe TD symptoms with a lower clinician and self-reported quality of life. Additional diagnostic criteria for TD also require that the patient have exposure to DRBAs for at least a few months, though exposure time can be shorter in some instances. ${ }^{4}$ Additionally, symptoms must last longer than 4-8 weeks, and if symptoms resolve within this time period, then the diagnosis is assumed to be neuroleptic-withdrawal emergent dyskinesia. This diagnostic distinction is significant because although remittance is possible, the symptoms of TD are often thought to be permanent. ${ }^{5}$

Tardive dyskinesia is most commonly associated with antipsychotic drugs. A recent meta-analysis including 41 different studies reported that the mean prevalence of TD is $25.3 \%$ among patients taking antipsychotic drugs. ${ }^{6}$ This study also stated that of the 11,493 patients involved in the analysis, approximately $77 \%$ had some type of schizophrenia-spectrum disorder. ${ }^{6}$ Antipsychotic drugs are typically classified into two main categories. These two main categories are typical antipsychotic drugs (also referred to as first-generation antipsychotics) and atypical antipsychotic drugs (sometimes referred to as second-generation antipsychotics). While typical antipsychotic drugs (TAPDs) were initially thought to have a significantly higher risk of inducing tardive dyskinesia and atypical antipsychotic drugs (AAPDs) were assumed to be free of risk, both classes of antipsychotic drugs are capable of inducing TD. ${ }^{7}$ Although TD is closely associated with antipsychotic drugs, other dopamine receptor-blocking agents have also been noted to cause TD. ${ }^{8}$ Examples of non-antipsychotic DRBAs to include metoclopramide and prochlorperazine, which are typically used as antiemetics. ${ }^{7}$

Until recently, effective pharmaceutical treatment for tardive dyskinesia has been scarce. However, recent investigations into the inhibition of vesicular monoamine transporters (VMAT) for the treatment of TD serve as a potential treatment option. VMAT is a membrane transporter that assists in the movement and release of monoamines. ${ }^{9}$ This transporter has two isoforms, VMAT1 and VMAT2. VMAT2 is found preferentially on monoaminergic cells within the CNS, thereby having therapeutic value for the treatment of TD. ${ }^{9}$ Valbenazine, a reversible and selective inhibitor of VMAT2, is currently one of the only FDA approved treatments for TD.

\section{TARDIVE DYSKINESIA EPIDEMIOLOGY}

Dopamine receptor-blocking agents (DRBA) such as typical antipsychotic drugs (TAPD) and atypical antipsychotic drugs (AAPD) are often used to treat conditions such as schizophrenia and bipolar disorder. However, patients treated with DRBAs are at risk for developing tardive dyskinesia (TD), and the link between TAPDs and TD is well-recognized. Although it was once widely thought that AAPDs did not cause TD, these drugs still put patients at risk. ${ }^{7}$ Additionally, the previous thought that AAPDs were low risk for TD has likely led to the expanded use of antipsychotics for conditions such as anxiety and depression. ${ }^{10}$ While a recent meta-analysis including 41 studies and 11,493 subjects reported that the prevalence of TD with AATPs (20.7\%) was lower than the prevalence of TD with TAPD (30.0\%), this still represents a significant portion of patients affected. 6 Overall, the mean prevalence of TD was $25.3 \% .^{6}$ Additionally, a cohort study reported that the annualized incidence of TD was 3.9\% for AAPDs and 5.5\% for TAPDs. ${ }^{11}$ Antipsychotic drugs, however, are often used by patients that require long-term therapy. Therefore both studies included patients assigned to AAPD groups that had previously used TAPDs at some point. ${ }^{6,11}$ Consequently, the values obtained in both studies may have been affected by previous TAPD therapy. Carbon et al. reported a TD prevalence of $20.7 \%$ for the entire AAPD group and a TD prevalence of $7.2 \%$ for the TAPD-naïve group. ${ }^{6}$ The variation in the reported incidence of TD highlights the need for additional epidemiological studies.

\section{PATHOPHYSIOLOGY}

The exact pathophysiology of tardive dyskinesia is unknown. However, several theories regarding the pathophysiology of TD have been suggested, including dopamine receptor supersensitivity, oxidative stress, and maladaptive plasticity. ${ }^{12}$ The dopamine supersensitivity and maladaptive plasticity theories are based on mechanisms involving DRBA binding to the D2 dopamine receptor within the indirect pathway of the basal ganglia. The indirect pathway inhibits the thalamus and motor cortex through dopaminergic projections from the substantia nigra that synapse with D2 receptors in the dorsal striatum. ${ }^{13}$ Dopamine typically binds to the D2 receptors and inhibits the GABA neurons within the dorsal striatum, preventing inhibition of the globus pallidus externa. This ultimately leads to activation of the thalamus and motor pathway. ${ }^{13}$ The dopamine supersensitivity and maladaptive plasticity theories, therefore, propose that the chronic blockade of D2 receptors within the dorsal striatum leads to hypersensitization and upregulation of D2 receptors, thus producing excess stimulation of the motor cortex, resulting in the hyperkinetic movements as observed in TD. ${ }^{14}$

However, a recent study used autoradiography to compare the amount of striatal dopamine D1, D2, and D3 receptors in monkeys with DRBA-induced TD versus monkeys without TD. ${ }^{15}$ The study reported that the binding of D2 receptors was relatively equal to the control group, with upregulation of $\mathrm{D} 3$ receptor binding in the striatonigral neurons. ${ }^{15}$ A second study used Western blots to analyze the serotonin, dopamine, and glutamate systems within monkeys treated with the DRBA haloperidol, further highlighting this pathway's complexity. ${ }^{16}$ In the monkeys that were treated with haloperidol, only the monkeys that did not develop TD showed changes in the levels of $5-\mathrm{HT}_{\mathrm{A} 2}$, 
metabotropic glutamate type 5, NMDA receptors, and monoamine transporter type $2 .{ }^{16}$ These findings underline the need for further investigation into the pathophysiology and likely highly complex nature of DRBA-induced TD.

\section{RISK FACTORS}

A recent observational study classified the commonly associated risk factors of tardive dyskinesia into two groups termed modifiable treatment-related factors and non-modifiable patient-related factors. ${ }^{17}$ One of the most important modifiable risk factors for the development of TD is the use of TAPDs vs. AAPDs. ${ }^{6,17}$ Specifically, TAPDs have been associated with a higher risk of TD occurring when compared to the use of AAPDs. Additional modifiable risk factors for TD include medical comorbidities, such as diabetes mellitus. ${ }^{17,18}$ Patients taking antipsychotics were reported to have a significantly higher risk of type 2 diabetes mellitus than patients not taking antipsychotics. ${ }^{18}$ Non-modifiable risk factors were broken into subgroups of patient-related and illness-related risk factors for TD. ${ }^{17}$ of the patient-related group, and older age has been widely accepted as an increased risk factor for the development of TD. ${ }^{6,7,17}$ Some studies have also cited that female patients seem to have an increased risk of developing TD. However, this claim is variable, and studies have also cited no significance between sex and TD. ${ }^{6,17}$ Additional patient-related factors that have been suggested to have an increased risk factor include race and genetic predisposition. One study reported a significant difference in the rates of TD by geographical region. ${ }^{6}$ Specifically, the prevalence of TD was $17.3 \%$ in Asia, $22.3 \%$ in Europe, $31.3 \%$ in the United States, and 31.8\% collectively in Australia, Africa, and the Middle East. While these values are technically significant, these values likely represent differences in regulation, clinical procedure, and possibly clinician evaluation of tardive dyskinesia. Moreover, the most important illness-related factor associated with a predisposed risk of TD is a longer illness duration. ${ }^{6,7,17}$ Overall, most of the risk factors reportedly associated with TD tend to have variable data, emphasizing the need for further studies.

\section{CLINICAL PRESENTATION}

Tardive dyskinesia is characterized by involuntary and repetitive oral-buccal-lingual movements (OBL) caused by chronic exposure to dopamine receptor-blocking agents. ${ }^{1}$ The movements associated with TD are considered complex and can include chewing movements and lip-smacking. ${ }^{2}$ While the classical presentation of tardive dyskinesia typically involves OBL movements, patients can also present with repetitive and stereotypic movements of the distal limbs. Patients can also report pain typically characterized as chronic burning or an unpleasant sensation around the mouth or genital regions. The onset of symptoms can occur after a few months and even after the discontinuation of treatment with antipsychotic drugs. ${ }^{19}$ TD is often permanent, and remission does not typically occur after symptoms are present. ${ }^{19}$ It is important to note that symptoms must be present 4-8 weeks post-discontinuation of a DRBA for the diagnosis to be considered tardive dyskinesia; otherwise, neuroleptic-withdrawal emergent dyskinesia should be considered. ${ }^{4}$ Additionally, antipsychotics often mask the symptoms of TD, thereby preventing a prompt diagnosis and potentially worsening the abnormal hyperkinetic movements. ${ }^{7}$

\section{CURRENT TREATMENTS FOR TARDIVE DYSKINESIA}

\section{WITHDRAWAL OF THE OFFENDING AGENT}

The first consideration for treating TD would be to stop the causative drug; however, this can be complicated by the possibility of transient worsening of symptoms upon abrupt drug removal or precipitate withdrawal emergent syndrome. ${ }^{20,21}$ There is also the concern that with the removal of the drug, the patient could have the return of their psychiatric symptoms. ${ }^{21,22}$ The evidence for the strategy of removing the offending agent is unclear, with some studies showing no significant differences between groups continued on DRBAs versus those given a placebo and other studies showing a worsening of TD symptoms upon removal of medication. ${ }^{23,24}$

\section{INCREASE OF THE OFFENDING AGENT}

Increasing the dose of an antipsychotic in response to TD can temporarily improve the symptoms; however, it has been found that this is a masking effect. Caution should be used as this can also increase the risk of other neurologic side-effects. $^{21,25}$

\section{SWITCHING FROM TYPICAL TO ATYPICAL ANTIPSYCHOTIC}

There has been research into changing from a typical antipsychotic to risperidone, olanzapine, quetiapine, and clozapine. These studies have yielded mixed results. Quetiapine was shown to decrease TD symptoms but only over time. ${ }^{21,26}$ It is unclear if this directly stops the previous offending agent or from the quetiapine itself. Both olanzapine and risperidone decreased symptoms over 24 weeks and may stem from the typical short-term improvement in symptoms when the dose of an antipsychotic is increased. ${ }^{21,27}$ In one study focusing on clozapine, regression of symptoms was observed with induction of clozapine, and the symptoms returned with discontinuation. ${ }^{28}$ This suggests an active role in the decrease of symptoms. ${ }^{21}$ Despite the positive results regarding $\mathrm{TD}$, the prevalence and severity of side effects makes clozapine unlikely as a first-line treatment. ${ }^{28}$ Risperidone was stated to probably be effective, and olanzapine is possibly effective in the treatment of TD. ${ }^{23,29}$

\section{AMANTADINE}

Amantadine is an NMDA-receptor antagonist that, both by itself and when given with neuroleptics, has been shown 
to reduce TD symptoms significantly. ${ }^{30,31}$ Most recently, a randomized, double-blind, placebo-controlled study using the Abnormal Involuntary Movement Scale (AIMS) showed that amantadine could reduce the total, facial and oral, extremity, and severity of AIMS scores over a 2-week treatment period. ${ }^{32}$ This is considered a short-term treatment, as it reduced TD symptoms within the first seven weeks. ${ }^{23,30}$

\section{GABA AGONISTS}

Clonazepam and diazepam, $\mathrm{GABA}_{\mathrm{A}}$ agonists, have been shown to reduce TD symptoms; however, this effect is lost over 3-9 months due to tolerance. ${ }^{33}$ However, in one open study, discontinuation of clonazepam for two weeks the drug demonstrated a return of anti-dyskinetic efficacy. ${ }^{23,33}$ These drugs are only considered short-term treatments for TD due to side-effects and development of tolerance. ${ }^{21,23}$

\section{ANTIOXIDANTS}

Antioxidants are protective against free-radical damage and have been studied for their effectiveness in TD to reverse rapid dopamine metabolism-induced free radicals. ${ }^{34}$ Studies involving Vitamin E have yielded mixed results, with the largest randomized control trial failing to show a significant difference between patients given Vitamin $\mathrm{E}$ versus those given placebo. ${ }^{35,36}$ Data is still considered insufficient for Vitamin $\mathrm{E}$ to be regarded as an effective treatment. ${ }^{23}$ Ginkgo biloba is another antioxidant that has shown promise as a treatment of TD in a randomized placebo-controlled trial and is considered an effective treatment. ${ }^{37}$ Although the study was highly significant, there is potential for criticism of the clinical significance of the findings, as the difference of the Abnormal Involuntary Movement Scale (AIMS) score between the two treatment arms was small.

\section{NON-PHARMACEUTICAL TREATMENT OPTIONS}

The use of botulinum toxin in the treatment of TD, specifically lingual-facial-buccal dyskinesia, is limited, but an open-label study and a case series both demonstrated botulinum to be effective in reducing TD symptoms with minimal adverse effects. ${ }^{38,39}$ However, data is still considered insufficient to support or refute botulinum toxin as an effective treatment for TD. ${ }^{23}$

Studies on the effects of electroconvulsive therapy (ECT) on TD in patients with pre-existing psychological disorders have shown mixed results. A recent retrospective study found a significant increase in AIMS scores in 39\% of the patients. ${ }^{40,41}$ Other evidence for ECT as a treatment for TD is based on case studies. Therefore there is insufficient data to support ECT as an effective treatment for TD. ${ }^{23}$

Data supporting deep brain stimulation (DBS) as a treatment for TD was initially only in case studies and series, although it did show positive results. ${ }^{42-44}$ A recent doubleblind evaluation in which there was DBS of the globus pallidus internal bilaterally was found to show a decrease in extrapyramidal symptoms without cognitive decline at 6 and 12 months. ${ }^{45}$ There have also been several recent case series that have demonstrated similar efficacy. ${ }^{46,47}$ It is now considered a possibly effective but invasive treatment, specifically in a patient who has failed to improve with previous treatment attempts. ${ }^{42,48}$

\section{VMAT2 INHIBITORS}

Tetrabenazine is a VMAT2 inhibitor currently used as a treatment for Huntington's disease. ${ }^{21}$ Although it has been found to have efficacy as a treatment for TD in a non-randomized, single-blinded study, the adverse effects of the drug limit its clinical use. ${ }^{48,49}$ Currently, tetrabenazine is only considered an option to treat TD in those unresponsive to all other pharmacologic interventions. ${ }^{23}$

Deutetrabenazine is similar to tetrabenazine, but it has a longer half-life and decreased serum availability of active metabolites due to the addition of deuterium. ${ }^{29,50}$ Supportive data on the effects of deutetrabenazine in TD patients have shown the drug's effectiveness and reduced side effects. ${ }^{51,52}$ Both during the trials and after as part of an open-label study, minimal adverse side effects were noted. Deutetrabenazine is considered an effective treatment for TD. ${ }^{29}$

\section{VALBENAZINE DRUG INFO}

Valbenazine, brand name Ingrezza, is a highly selective VMAT2 inhibitor approved by the FDA in 2017 to treat TD in adults. ${ }^{53}$ Tetrabenazine, a similar drug approved for the treatment of Huntington's disease, is broken down into the active metabolites, alpha-HTBZ, and beta-HTBZ. ${ }^{54}$ The beta isomer functions as a $\mathrm{D}_{2}$ dopamine receptor antagonist, which induces sedation and parkinsonism. The alpha isomer acts as a VMAT2 inhibitor which is the action of interest in treating TD. ${ }^{55}$ Valbenazine is a purified prodrug of the alpha isomer, allowing it to be highly selective in inhibiting VMAT2 with a lower risk of adverse side effects due to off-target receptor binding. It also is broken down more slowly, leading to a longer half-life, allowing for administration once per day. ${ }^{55,56}$ In a phase 3 randomized, doubleblind placebo-controlled trial comparing valbenazine to a placebo, patients with moderate to severe TD with a history of mood disorders showed improvement of their TD. ${ }^{57}$ Over six weeks, patients were randomly assigned to receive either a daily dose of placebo, $40 \mathrm{mg}$ of valbenazine, or $80 \mathrm{mg}$ of valbenazine. At the end of the six weeks, significant reductions in AIMS scores were seen in both the $80 \mathrm{mg}$ group and the $40 \mathrm{mg}$ group compared to the placebo. ${ }^{57}$

Currently, the FDA states possible adverse reactions include balance disorders, headache, anticholinergic effects, akathisia, vomiting, nausea, and arthralgia. ${ }^{58}$ The most common side effects have been somnolence and QT prolongation. Clinically significant drug interactions include Monoamine Oxidase Inhibitors (MAOIs), strong CYP3A4 inhibitors, strong CYP3A4 inducers, and digoxin. ${ }^{58}$ Although the data is limited on the effect of valbenazine in pregnant and breastfeeding patients, studies with rats suggest a potential increase in the number of stillborn pups and postnatal pup mortalities. ${ }^{58}$ Pregnant women should be advised of the risks, and lactating women should advise not to take Ingrezza while breastfeeding. There have been no studies into 
the efficacy and safety of Ingrezza in the pediatric population. Ingrezza is considered safe with no need for dose adjustments in the geriatric population and people with mild to moderate renal impairment. Although Ingrezza does not undergo primary renal clearance, it should not be taken in people with severe renal impairment. ${ }^{58}$ The dose of Ingrezza should be reduced in patients with moderate to severe hepatic insufficiency. Ingrezza is currently available in a $40 \mathrm{mg}$ or $80 \mathrm{mg}$ capsule to be taken once daily. ${ }^{58}$ Although short term studies have shown safe and efficacious results, studies on the long term effects of valbenazine are still necessary. 57

\section{MECHANISM OF ACTION}

Valbenazine is made from the alpha isomer of tetrabenazine, the most potent and selective active metabolite, coupled with valine which allows for a prolonged release and rapid activation to $(+)$ alpha dihydrotetrabenazine $((+)-$ alpha HTBZ). ${ }^{57,59,60}$ Valbenazine acts to reversibly inhibit VMAT2, a transmembrane protein responsible for uptake and concentration of several monoamines, including dopamine, in presynaptic vesicles in the central nervous system (CNS). There is little to no binding of valbenazine or its metabolites to VMAT1, which is located peripherally. Inhibition of VMAT2 by valbenazine and its metabolites, specifically (+)-alpha HTBZ, has been shown to preferentially prevent dopamine uptake into synaptic vesicles, leading to an increase of dopamine breakdown by monoamine oxidase (MAO) in the cytoplasm of the presynaptic neuron. ${ }^{54,61}$ This leads to an overall decrease in the availability of dopamine in presynaptic cells in the motor striatum. ${ }^{62}$ This allows for a therapeutic decrease in the amount of dopaminergic stimulation of the indirect pathway of the motor striatum, in contrast to blockage of the dopamine D2 receptors. Chronic use of antipsychotics that block the D2 receptors in the indirect pathway of the motor striatum leads to upregulation and hypersensitization of the receptors. ${ }^{63}$ If the dose of the D2 receptor antagonist is increased in response to $\mathrm{TD}$, leading to a transient improvement in symptoms at the cost of an overall increase in the TD and other neurologic symptoms. 64

Treatment of TD by inhibition of VMAT2 inhibitors avoids the upregulating and hypersensitization of dopamine receptors in response to chronic $\mathrm{D}_{2}$ dopamine receptor blockers. ${ }^{63}$ VMAT2 inhibition decreases the amount of dopamine available to interact with D1 and D2 receptors in the motor striatum. The binding of dopamine to the D1 receptors activates the motor striatum's direct pathway, leading to an increase in movement, known as the "go signal.” The indirect pathway is the inhibitory pathway, known as the "stop signal," and dopamine binding to D2 inhibits the indirect pathway. Hypersensitivity of D2 receptors due to chronic blockage leads to increased indirect pathway inhibition, causing an overall increase in unwanted movement. VMAT2 inhibition by valbenazine decreases the available dopamine without blocking the receptors allowing for increased indirect pathway activity, the "stop signal," and reduced activity in the direct pathway, the "go signal.”61,63,65 This overall blockade of movement is proposed to reduce TD symptoms.

\section{PHARMACOKINETICS}

Although it is not required, if valbenazine is taken with food, patients should be aware that high-fat meals will decrease the $\mathrm{C}_{\max }$ of valbenazine by $47 \% .{ }^{58}$ There is not a similar decrease in the $\mathrm{C}_{\max }$ of (+)-alpha HTBZ. After it is absorbed, valbenazine is metabolized via hydrolysis of the valine ester and mono-oxidation by CYP3 A4/5 to form (+)-alpha HTBZ and NBI-136110, respectively. ${ }^{57,58}(+)$-alpha HTBZ is then further metabolized by CYP2D6. ${ }^{53,58}$

Both valbenazine and its active metabolites, specifically (+)-alpha HTBZ and NBI-136110, bind reversibly to VMAT2 with limited or no binding to VMAT1 or dopaminergic, serotonergic, adrenergic, histaminergic, or muscarinic receptors. ${ }^{58}$ Additionally, (+)-alpha HTBZ was found to have the most potent effect, with valbenazine and NBI-136110 having lower affinity. ${ }^{59}$ These findings were confirmed by examining the binding of valbenazine and metabolites in rat striatum and human platelet homogenates. This finding was further confirmed using radioligand-binding assays in rat forebrains. ${ }^{59}$ The specificity of the binging to VMAT2 was confirmed by multitarget activity screening of valbenazine and its metabolites. Binding to more than 80 targets was tested and showed that they did not inhibit ligand binding to the tested targets by more than 50\%. ${ }^{59}$ The oral bioavailability of valbenazine is approximately $49 \%$ of the taken dose. ${ }^{58}$ Valbenazine has a time to maximum plasma concentration $\left(_{\text {Tmax }}\right.$ ) ranging from 30 minutes to an hour. ${ }^{53,58,59}$ The active metabolite, (+)-alpha HTBZ, reaches maximum plasma concentration $\left(\mathrm{C}_{\max }\right)$ in 4 to 8 hours. ${ }^{58}$ The $\mathrm{C}_{\max }$ and area under the curve (AUC) of both valbenazine and (+)-alpha HTBZ increased proportionally to the increase in dose between 50 and $100 \mathrm{mg} .{ }^{66}$ Valbenazine and (+)-alpha HTBZ demonstrates plasma protein binding of approximately $99 \%$ and $64 \%$, respectively. 53,58 Systemic accumulation of valbenazine and (+)-alpha HTBZ was about 1.5 fold and between 2.3-2.6 fold, respectively. ${ }^{66}$ Steady-state of both valbenazine and (+)-alpha HTBZ were reached by day $8 .{ }^{66}$ The peak-to-trough fluctuation of valbenazine and $(+)$-alpha HTBZ is approximately $250 \%$ and $68 \%$, respectively. The decreased fluctuation of $(+)$-alpha HTBZ is thought to be because it is formed and eliminated at a more gradual pace. 66

Valbenazine has an average plasma clearance of $7.2 \mathrm{~L} /$ hour with approximately $60 \%$ excreted in the urine, $30 \%$ excreted in feces, and less than $2 \%$ excreted as unchanged valbenazine and (+)-alpha HTBZ. ${ }^{53,58}$ Both valbenazine and its metabolites have similar half-lives of approximately 20 hours that did not change after repeat dosage suggesting a formation rate-limited clearance. ${ }^{59,66}$ This half-life is what allows for dosing once a day. ${ }^{57}$

\section{CLINICAL SAFETY AND EFFICACY}

Several double-blind, randomized, controlled trials have shown valbenazine to have significant efficacy over placebo and be generally well-tolerated by patients and not to worsen any underlying psychiatric conditions. Additionally, in extension studies of valbenazine, patients were shown to have to worsen TD symptoms following discontinuation 
of the medication, further suggesting that valbenazine is efficacious in the treatment of TD. Finally, although the prescribing information for valbenazine includes a warning that the medication might prolong the QTc interval, especially when used concomitantly with medications that inhibit CYP2D6 or CYP3A4 or in CYP2D6 poor metabolizers, clinical studies show no statistically significant prolongation of QTc as compared to placebo in the recommended dosing amounts. ${ }^{67}$

In a randomized, double-blind, placebo-controlled, dose-titration study, 100 medically and psychiatrically stable patients, aged 18-85, with clinically diagnosed schizophrenia, schizoaffective disorder, or mood disorder, and neuroleptic-induced moderate to severe TD were treated for six weeks with either placebo or valbenazine. ${ }^{55}$ The starting dose of $25 \mathrm{mg}$ daily could be escalated by $25 \mathrm{mg}$ every two weeks as needed to a maximum of $75 \mathrm{mg}$ based on the clinical judgment of the blinded Physician Investigator (PI). It was noted that $76 \%$ of subjects taking the active medication were escalated to the maximum dose, and $80 \%$ of subjects assigned to the placebo group reached the maximum dose. Clinical efficacy endpoints were defined as a change in Abnormal Involuntary Movement Scale (AIMS) score from baseline and a difference in the Clinical Global Impression of Change-TD (CGI-TD) from baseline as rated by the blinded PI. ${ }^{55}$ Of the 100 patients, ten patients, five in the placebo arm and five in the treatment arm, were withdrawn from the trial post-randomization; however, none of the discontinuations were attributed to the study medications. At the end of six weeks, $48.9 \%$ of participants taking the active medication had $\mathrm{a} \geqslant 50 \%$ reduction in their AIMS score from baseline compared to $18.2 \%$ of patients in the placebo group $(p=0.0005) .67 \%$ of patients taking the active drug versus $16 \%$ of subjects in the placebo group were rated "much improved" or "very much improved" on CGI-TD scoring $(p<0.0001) .{ }^{68}$ Although two patients in the placebo arm of the study experienced significant treatmentemergent adverse events (TEAEs), including one who died of a myocardial infarction and was discontinued from the study, no subjects taking valbenazine experienced severe TEAEs. ${ }^{55}$ The overall incidence of TEAEs was higher in patients taking the active medication (49\%) than those taking placebo (32.7\%). The most commonly reported AEs reported in the valbenazine arm of the study were fatigue and headache (9.8\% for both). The most frequently reported AEs were constipation and urinary retention (6.1\% for both) in the placebo arm. No safety concerns for drug-induced akathisia, parkinsonism, depression, or suicidal ideation and behavior were noted in either arm of the study. 55

In the KINECT 3 study, a phase 3, randomized, doubleblind, placebo-controlled, fixed-dose study, 234 patients with schizophrenia or schizoaffective disorder and a DSM diagnosis of dopamine receptor blocker-induced tardive dyskinesia for three months before screening were randomized in a 1:1:1 distribution to receive one of the following once daily: placebo, $40 \mathrm{mg}$ valbenazine, or $80 \mathrm{mg}$ valbenazine. ${ }^{56}$ Clinical efficacy endpoints were defined as a change in Abnormal Involuntary Movement Scale (AIMS) score from baseline and a change in the Clinical Global Impression of Change-TD (CGI-TD) from baseline. Of the 234 patients randomized, seven in the placebo group, 13 in the $40 \mathrm{mg}$ valbenazine group, and nine in the $80 \mathrm{mg}$ group discontinued the study. ${ }^{56}$ Additionally, two patients in the $80 \mathrm{mg}$ valbenazine arm received dosage decreases to $40 \mathrm{mg}$, and three patients in the placebo group and one in the 40 mg group received dummy decreases. At week 6 , the percentage of patients with $a \geqslant 50 \%$ reduction in their AIMS scores from baseline in both valbenazine arms of the study was significantly increased from placebo. However, fewer patients in the $40 \mathrm{mg}$ group than the $80 \mathrm{mg}$ group showed improvement, $23.8 \%(p=0.002)$ and $40 \%(p<0.001)$ of patients respectively, compared with $8.7 \%$ in the placebo group. ${ }^{56}$ Although there were no significant differences in CGI-TD score between the active medication and placebo arms in the intent-to-treat population, a significant difference was found between both the valbenazine arms and placebo arm in the per-protocol population $(p=0.011$ for both dose groups compared against placebo). 13 patients in total experienced treatment-emergent severe adverse events (TEAEs) and seven were discontinued from the study, including two in the placebo arm, one in the $40 \mathrm{mg}$ group, and four in the $80 \mathrm{mg}$ group; however, none of the events were assessed as related to the study drug, except for one patient in the $80 \mathrm{mg}$ valbenazine arm who experienced a reactivation of viral hepatitis. ${ }^{56}$ The most common adverse effects in both the $40 \mathrm{mg}$ and $80 \mathrm{mg}$ valbenazine groups were somnolence (5.6\% and $5.1 \%$, respectively) and akathisia ( $4.2 \%$ and $2.5 \%$, respectively). The most common adverse effects in the placebo group were suicidal ideation (5.3\%) and somnolence (3.9\%). There was one suicide attempt during the duration of the study. However, it was assessed not to be related to the study drug as the man had multiple previous suicide attempts, had only received one dose of the study drug ( $80 \mathrm{mg}$ ), and had symptoms of dysarthria and a fall one day before starting the study drug - the patient reported that he thought he had suffered a stroke and did not want to live. ${ }^{56}$ Nine participants reported worsening suicidal ideation, but these were relatively evenly spread among all three treatment arms: two patients in the $80 \mathrm{mg}$ active medication group, three patients in the $40 \mathrm{mg}$ group, and four patients in the placebo group. No safety concerns for worsening psychiatric condition were reported for any group in the study. ${ }^{56}$

A review paper of two double-blind, randomized, placebo-controlled trials of deutetrabenazine and four double-blind trials of valbenazine, including the affiliated open-label or dose-blinded extensions, found that both VMAT2 inhibitors were significantly better than placebo at controlling TD and well-tolerated in all studies. ${ }^{68}$ There were no observed increases in adverse effects from the active medications compared to placebo in any of the trials. Additionally, four-week discontinuation studies following the completion of the 48-week trials showed regression towards the subjects' baseline TD symptoms. ${ }^{68}$

198 of the 205 patients who completed the original 6-week study were enrolled in the 42 -week continuation of the KINECT 3 trial, and 124 completed the continuation period. ${ }^{69}$ The study's primary purpose was to determine the long-term safety of valbenazine - subjects' vital signs, 12-lead electrocardiogram, and laboratory assessments were obtained at each visit in addition to descriptions of any TEAEs. The Columbia Suicide Severity Rating Scale (C- 
SSRS), Positive and Negative Syndrome Scale (PANSS), Calgary Depression Scale for Schizophrenia (CDSS), Young Mania Rating Scale (YMRS), and Montgomery-Asberg Depression Rating Scale (MADRS) were used to assess psychiatric stability. The Barnes Akathisia Rating Scale (BARS) and the Simpson-Angus Scale (SAS) were used to determine treatment-emergent akathisia and parkinsonism. ${ }^{69}$ Continuing effects on symptoms of TD were measured on the AIMS scale and CGI-TD as before and were generally similar to those described for the original 6-week study period. Subjects were either re-randomized to valbenazine $40 \mathrm{mg}$ or 80 $\mathrm{mg}$ daily if they had received a placebo or continued on their current dose of valbenazine for the extended duration. ${ }^{69}$ Of note, 74 patients were discontinued from the study before week 48 . Of these, $15.7 \%$ were discontinued due to AEs, $8.6 \%$ withdrew consent, and $7.1 \%$ were lost to follow-up. ${ }^{69}$ The only AEs causing discontinuation of $>2$ patients were somnolence and suicidal ideation. Three patients in the 80 mg group were discontinued due to somnolence. Two patients in the $40 \mathrm{mg}$ group and one patient in the $80 \mathrm{mg}$ group experienced suicidal ideation, significant enough to stop the medication. The total incidence of TEAEs in the study duration was $69.2 \%$, and the incidence of severe TEAEs was $14.6 \%{ }^{69}$ Two participants in the $40 \mathrm{mg}$ valbenazine arm experienced akathisia. One patient in the $80 \mathrm{mg}$ arm experienced parkinsonism; BARS and SAS score changes were not clinically significant during the extension period. Additionally, scores on all the psychiatric stability measurement indices remained stable throughout the extension period. ${ }^{69}$

Of the 124 patients who completed the extension period of the KINECT 3 trial, 121 also completed the discontinuation period wherein they stopped taking valbenazine and were allowed to wash out over four weeks. ${ }^{70}$ Analysis found that AIMS scores at week 52, following the 4-week washout, were higher than at the end of the original 6-week study period. Similarly, the responder rate, defined as a $\geqslant 50 \%$ reduction in AIMS score from baseline, at week 52 was lower than at week six for the $80 \mathrm{mg}$ valbenazine arm, $16.7 \%$ after washout compared to $38.5 \%$ at week six and $56 \%$ at week 48.70 The responder rate in the $40 \mathrm{mg}$ arm (27.8\%) remained higher after washout than at week six. However, it was lower than at week 48 (19\% and 33.3\%, respectively).

A review paper of all available clinical studies in 2017 found that, although valbenazine may prolong the QTc interval, especially in patients who are poor CYP2D6 metabolizers or those taking concomitant medications that either prolong QTc interval or cause CYP2D6 inhibition, there were no clinically significant alterations in EKG results of participants in clinical trials, including in patients who were taking medications known to prolong the QTc interval potentially. ${ }^{71}$ In an analysis of two studies of healthy male volunteers, no changes to the QTc interval were noted. ${ }^{63} \mathrm{An}$ analysis of the pooled data from all three KINECT trials as well as the 48-week extension period of the KINECT 3 trial found that there was no statistically significant difference in the number of cardiac-related TEAEs between any dose of valbenazine and placebo. ${ }^{67}$ In the 6-week double-blind, placebo-controlled trial, there were a total of five cardiacrelated TEAEs, including myocardial infarction in one participant in the placebo arm of the trial and sudden death possibly resulting from a cardiovascular event in one par- ticipant with multiple cardiac risk factors in the $80 \mathrm{mg}$ valbenazine group. ${ }^{56}$ Other cardiac-related TEAEs were chest pain ( $n=1,40 \mathrm{mg}$ valbenazine), bradycardia ( $n=1,40 \mathrm{mg}$ valbenazine), and increased blood pressure ( $n=1,80 \mathrm{mg}$ valbenazine). Additionally, at week 6 , there was no statistically significant difference in QTc prolongation between either active drug arm and placebo. Those who took valbenazine $40 \mathrm{mg}$ daily showed a $1.1 \mathrm{~ms}$ mean change, valbenazine 40 mg daily showed a $2.1 \mathrm{~ms}$ mean change, and placebo showed a $1.3 \mathrm{~ms}$ mean change; all $\mathrm{p}$-values were $>0.05 .67$ In the KINECT 3 extension period, three cardiac-related TEAEs were leading to discontinuation (syncope, $n=2,1$ in each arm; cardiac failure, $n=1,80 \mathrm{mg}$ valbenazine), and the most common cardiac TEAEs were chest pain ( $n=4,2$ in each arm) and syncope ( $n=3,40 \mathrm{mg} ; n=1,80 \mathrm{mg}) .{ }^{56}$ Further, although more participants in the $80 \mathrm{mg}$ group had a QTc increase $>30 \mathrm{~ms}$ from baseline $(24 \%)$ or a QTc $>450 \mathrm{~ms}$ (22\%) than in the $40 \mathrm{mg}$ group (14.7\% and $13.7 \%$, respectively), few participants had a significant increase in QTc (>60ms increase from baseline) or a QTc $>480 \mathrm{~ms}$. There was no significant difference between the $40 \mathrm{mg}$ and $80 \mathrm{mg}$ groups: QTc $>60 \mathrm{mg}$ increase $3.2 \%$ and $3.0 \%$, respectively, and QTc $>480 \mathrm{~ms} 2.1 \%$ and $3.0 \%$, respectively. ${ }^{67}$ Finally, subgroup analyses revealed no exacerbating effects of valbenazine on QTc prolongation in the population already taking medications known to prolong QTc (74.3\% of the pooled study populations). Mean QTc values for this group were $411.2 \mathrm{~ms}$, $414 \mathrm{~ms}$, and $413 \mathrm{~ms}$ at baseline and $412.2 \mathrm{~ms}, 413.7 \mathrm{~ms}$, and $413.6 \mathrm{~ms}$ at week 6 for placebo, $40 \mathrm{mg}$ valbenazine, and $80 \mathrm{mg}$ valbenazine, respectively. This difference was not statistically different from those for the group not taking concomitant medications known to prolong QTc: $414.1 \mathrm{~ms}$, $416.3 \mathrm{~ms}, 412.6 \mathrm{~ms}$ at baseline, and $417.9 \mathrm{~ms}, 418.7 \mathrm{~ms}$, and $418.3 \mathrm{~ms}$ at week 6 for placebo, $40 \mathrm{mg}$ valbenazine, and $80 \mathrm{mg}$ valbenazine, respectively. ${ }^{67}$ No analysis of QTc prolongation in patients who are poor CYP2D6 metabolizers was performed due to the low number of study participants with that characteristic (4.8\% of study participants). At this time, CYP genotyping is not required or recommended for patients who might be prescribed valbenazine. Table 1 summarizes the studies discussed in this section.

\section{CONCLUSION}

Tardive dyskinesia is a severe and potentially permanent side effect of dopamine receptor-blocking agents. The most effective treatment method for tardive dyskinesia is prevention. The use of any medication known to cause tardive dyskinesia should only be used if no other treatment is indicated. Additionally, dopamine receptor-blocking agents should only be used for the shortest amount of time therapeutically possible. Patients should be regularly monitored by physicians to prevent the onset or the worsening of tardive dyskinesia symptoms.

Unfortunately, most patients prescribed dopamine receptor-blocking agents are being treated for lifelong illnesses such as schizophrenia and bipolar disorder. By nature, these conditions often require the use of antipsychotic drugs for effective therapy and are typically lifelong, thereby necessitating the chronic use of dopamine receptor-blocking agents. Previously recommended treatments 
Table 1. Clinical Safety and Efficacy

\begin{tabular}{|c|c|c|c|}
\hline Author (Year) & Groups Studied and Intervention & Results and Findings & Conclusions \\
\hline 55 & $\begin{array}{l}100 \text { patients were treated with } \\
\text { either placebo }(n=49) \text { or } \\
\text { valbenazine }(n=51) \text {. Endpoints } \\
\text { were a change in AIMS score } \\
\text { from baseline and a change in } \\
\text { CGI-TD score from baseline as } \\
\text { rated by the blinded PI. }\end{array}$ & $\begin{array}{l}48.9 \% \text { of participants taking the } \\
\text { active medication had a } \geq 50 \% \\
\text { reduction in their AIMS score } \\
\text { from baseline compared to } \\
18.2 \% \text { of patients in the placebo } \\
\text { group. } 67 \% \text { of patients taking the } \\
\text { active drug versus } 16 \% \text { of } \\
\text { subjects in the placebo group } \\
\text { were rated "much improved" or } \\
\text { "very much improved" on the } \\
\text { CGI-TD scale. No subjects taking } \\
\text { valbenazine experienced severe } \\
\text { TEAEs. Two patients in the } \\
\text { placebo arm of the study } \\
\text { experienced significant TEAEs. } \\
\text { The overall incidence of TEAEs } \\
\text { was higher in patients taking the } \\
\text { active medication ( } 49 \% \text { ) than } \\
\text { those taking placebo ( } 32.7 \% \text { ). No } \\
\text { safety concerns for drug-induced } \\
\text { akathisia, parkinsonism, } \\
\text { depression, or suicidal ideation } \\
\text { and behavior were noted in } \\
\text { either arm of the study. }\end{array}$ & $\begin{array}{l}\text { Valbenazine is well tolerated and } \\
\text { significantly more effective than } \\
\text { placebo in the treatment of } \\
\text { tardive dyskinesia. }\end{array}$ \\
\hline 56 & $\begin{array}{l}234 \text { patients were randomized in } \\
\text { a 1:1:1 distribution to receive } \\
\text { one of the following once daily: } \\
\text { placebo, } 40 \mathrm{mg} \text { valbenazine, or } \\
80 \mathrm{mg} \text { valbenazine. Endpoints } \\
\text { were a change in AIMS score } \\
\text { from baseline and a change in } \\
\text { CGI-TD score from baseline as } \\
\text { rated by the blinded PI. }\end{array}$ & $\begin{array}{l}23.8 \% \text { of patients taking } 40 \mathrm{mg} \\
\text { daily and } 40 \% \text { of patients taking } \\
80 \mathrm{mg} \text { daily had a } \geq 50 \% \\
\text { reduction in their AIMS score } \\
\text { from baseline compared to } 8.7 \% \\
\text { of patients in the placebo group. } \\
\text { A significant improvement in } \\
\text { CGI-TD scores was also seen in } \\
\text { both active medication groups } \\
\text { when compared to placebo, but } \\
\text { only in the per-protocol } \\
\text { population. There was no } \\
\text { appreciable increase in TEAEs in } \\
\text { the treatment groups compared } \\
\text { to the placebo, and all treatment } \\
\text { groups remained psychiatrically } \\
\text { stable for the duration of the } \\
\text { trial. }\end{array}$ & $\begin{array}{l}\text { Valbenazine is significantly more } \\
\text { effective than placebo in the } \\
\text { treatment of tardive dyskinesia, } \\
\text { and effects are dose-dependent. } \\
\text { The medication is well-tolerated } \\
\text { and does not exacerbate existing } \\
\text { psychiatric conditions. }\end{array}$ \\
\hline 69 & $\begin{array}{l}205 \text { patients were either } \\
\text { randomized 1:1 to } 40 \mathrm{mg} \text { or } \\
80 \mathrm{mg} \text { daily of valbenazine or } \\
\text { continued their dose from the } \\
\text { 6-week KINECT } 3 \text { study. } \\
\text { Endpoints were study } \\
\text { discontinuation due to TEAEs or } \\
48 \text { weeks from the beginning of } \\
\text { the extension period. }\end{array}$ & $\begin{array}{l}\text { 69.2\% of participants } \\
\text { experienced TEAEs during the } \\
\text { study period, leading to the } \\
\text { discontinuation of } 15.7 \% \text { of } \\
\text { participants. The incidence of } \\
\text { severe TEAEs was } 14.6 \% \text {. BARS } \\
\text { and SAS score changes were not } \\
\text { clinically significant during the } \\
\text { extension period. All psychiatric } \\
\text { stability measurement indices } \\
\text { remained stable throughout the } \\
\text { extension period. Continuing } \\
\text { measurements of AIMS and CGI- } \\
\text { TD scores remained similar to } \\
\text { the original 6-week trial period. }\end{array}$ & $\begin{array}{l}\text { Valbenazine is effective long- } \\
\text { term for the control of TD } \\
\text { symptoms and has a low } \\
\text { incidence of severe TEAEs. It } \\
\text { does not exacerbate existing } \\
\text { psychiatric conditions, nor does } \\
\text { it induce akathisia or } \\
\text { parkinsonism. }\end{array}$ \\
\hline 70 & $\begin{array}{l}121 \text { of the } 124 \text { patients who } \\
\text { completed the } 48 \text {-week KINECT } \\
3 \text { extension period also } \\
\text { completed the } 4 \text {-week washout } \\
\text { period and follow-up study. } \\
\text { Endpoints were AIMS scores and } \\
\text { CGI-TD after a 4-week drug } \\
\text { washout period. }\end{array}$ & $\begin{array}{l}\text { AIMS scores at week } 52 \text { were } \\
\text { higher than at the end of the } \\
\text { original } 6 \text {-week study period, } \\
\text { and the percentage of } \\
\text { responders decreased to } 16.7 \% \\
\text { after washout compared to } \\
38.5 \% \text { at week six and } 56 \% \text { at } \\
\text { week } 48 \text { in the } 80 \mathrm{mg} \\
\text { valbenazine group. In the } 40 \mathrm{mg} \\
\text { group, the responder rate was }\end{array}$ & $\begin{array}{l}\text { Valbenazine is effective at } \\
\text { controlling symptoms of TD, and } \\
\text { symptoms will recur when the } \\
\text { medication is discontinued. }\end{array}$ \\
\hline
\end{tabular}


such as antipsychotic drug withdrawal and increases in DRBA dose only further exacerbate symptoms of TD. Similarly, treatment with GABA agonists such as clonazepam and diazepam only provides short-term relief of symptoms and puts patients at risk for developing tolerance to this drug class.

The continued use of dopamine receptor-blocking agents, combined with the high prevalence of tardive dyskinesia, has prompted an inquiry into effective new treatments for this condition. Consequently, vesicular monoamine transporter inhibitors have shown recent efficacious results. Valbenazine, also known as Ingrezza, is a relatively safe pharmaceutical therapy to treat tardive dyskinesia induced by dopamine receptor-blocking agents. Relative to other VMAT inhibitors such as tetrabenazine and deutetrabenazine, valbenazine is highly selective for VMAT2 inhibition and shows little to no binding of VMAT1 or other monoaminergic receptors within the CNS. The selective nature of these drugs and the limited renal and liver toxicity and single daily dose make valbenazine a particularly effective therapy for tardive dyskinesia.

\section{DISCLOSURES}

The authors have nothing to disclose.

\section{FUNDING}

No external funding source was used for the generation of this publication.

Submitted: June 02, 2021 EST, Accepted: June 16, 2021 EST 
Table 2. Comparative Studies

\begin{tabular}{|c|c|c|c|}
\hline Citation & Groups Studied and Intervention & Results and Findings & Conclusions \\
\hline 68 & $\begin{array}{l}\text { Literature search performed on } \\
\text { PubMed, ClinicalTrials.gov, } \\
\text { Cochrane library, and FDA website } \\
\text { produced } 6 \text { clinical trials included } \\
\text { in the study. The quality of the } \\
\text { clinical trials was assessed using } \\
\text { the Cochrane Collaboration risk- } \\
\text { of-bias tool. Meta-analysis was } \\
\text { performed, and the primary } \\
\text { endpoint was the calculated } \\
\text { standard mean difference (SMD). } \\
\text { Other endpoints were the } \\
\text { calculated weighted mean } \\
\text { difference (WMD), risk ratio (RR) } \\
\text { and number needed to treat } \\
\text { (NNT), and number needed to } \\
\text { harm (NNH) as applicable. }\end{array}$ & $\begin{array}{l}\text { Five of the six studies had a low } \\
\text { risk of bias, and one had an unclear } \\
\text { risk of bias due to a lack of } \\
\text { methodological information. } \\
\text { Results confirmed efficacy of } \\
\text { valbenazine for TD with SMD } \\
=-0.58, \text { WMD }=-2.07, \mathrm{RR}=3.05, \\
\mathrm{NNT}=5 . \text { No increased risk of AEs } \\
\text { over placebo was noted in the } \\
\text { meta-analysis of safety data from } \\
\text { the pooled trials. }\end{array}$ & $\begin{array}{l}\text { Valbenazine is more effective than } \\
\text { placebo at treating TD, and has no } \\
\text { increased risk of AEs. }\end{array}$ \\
\hline 71 & $\begin{array}{l}\text { A review and synthesis of all } \\
\text { available clinical data from } \\
\text { PubMed, US ClinicalTrials.gov, and } \\
\text { EMBASE, as well as slides } \\
\text { requested from the manufacturers } \\
\text { (Neurocrine Biosciences) and the } \\
\text { product prescribing information } \\
\text { label. NNT and NNH comparing } \\
\text { valbenazine and placebo were } \\
\text { calculated as applicable. }\end{array}$ & $\begin{array}{l}\text { From the pooled subject data, this } \\
\text { review found that the NNT for } \\
\text { valbenazine vs. placebo was } 5 \text {, the } \\
\text { NNH for all pooled TEAEs was 76, } \\
\text { and the likelihood to be helped or } \\
\text { harmed (LHH) was (NNH/ NNT or } \\
76 / 5 \text { ) 15.2. Additionally, no } \\
\text { clinically significant cardiac AEs or } \\
\text { changes to EKG were noted in the } \\
\text { pooled subject data. }\end{array}$ & $\begin{array}{l}\text { Valbenazine is significantly more } \\
\text { efficacious than placebo in the } \\
\text { treatment of tardive dyskinesia } \\
\text { and is well-tolerated across pooled } \\
\text { data from several clinical trials. }\end{array}$ \\
\hline 67 & $\begin{array}{l}\text { Data from the KINECT, KINECT 2, } \\
\text { and KINECT } 3 \text { 6-week trials, as } \\
\text { well as the } 42 \text { week extension } \\
\text { period of the KINECT } 3 \text { trial, were } \\
\text { pooled ( } 400 \text { subjects total) and the } \\
\text { incidence of cardiac TEAEs } \\
\text { analyzed by aggregating the } \\
\text { MedDRA terms cardiac failure, } \\
\text { chest pain, ECG QT prolonged, } \\
\text { myocardial infarction, sudden } \\
\text { death, syncope, and torsades de } \\
\text { pointes/QT prolongation from all } \\
\text { studies. Additionally, the incidence } \\
\text { of orthostatic hypotension and } \\
\text { hypotension TEAEs were } \\
\text { aggregated using the terms blood } \\
\text { pressure decreased, dizziness, } \\
\text { dizziness postural, fall, } \\
\text { hypotension, orthostatic } \\
\text { hypotension, orthostatic } \\
\text { intolerance, presyncope, and } \\
\text { syncope. }\end{array}$ & $\begin{array}{l}\text { 11.8\% of subjects had an existing } \\
\text { cardiac disorder before being } \\
\text { enrolled in one of the studies, and } \\
74.3 \% \text { of the pooled study } \\
\text { populations took a concomitant } \\
\text { medication known to prolong QTc. } \\
\text { No statistically significant } \\
\text { difference between the incidence } \\
\text { of cardiac TEAEs was found } \\
\text { between the groups receiving } \\
\text { valbenazine and placebo. At week } \\
\text { 6, there was no statistically } \\
\text { significant difference in QTc } \\
\text { prolongation between either } \\
\text { active drug arm and placebo in any } \\
\text { of the studies. }\end{array}$ & $\begin{array}{l}\text { There is a minimal increased risk of } \\
\text { cardiac TEAEs due to treatment } \\
\text { with valbenazine. It is unlikely to } \\
\text { prolong QTc, even in patients } \\
\text { taking concomitant medications } \\
\text { known to prolong QTc. }\end{array}$ \\
\hline 63 & $\begin{array}{l}\text { Two studies of healthy adult male } \\
\text { volunteers ( } 56 \text { pooled subjects) } \\
\text { not taking any other medications } \\
\text { were analyzed to determine the } \\
\text { safety, tolerability, and } \\
\text { pharmacokinetics (PK) of } \\
\text { valbenazine. PK parameters were } \\
\text { analyzed using liquid } \\
\text { chromatography to determine } \\
\text { plasma concentrations, and } \\
\text { standard noncompartmental } \\
\text { methods and WinNonlin } \\
\text { Professional v } 5.2 \text { were used to } \\
\text { calculate the parameters. }\end{array}$ & $\begin{array}{l}\text { There were no cardiac TEAEs, or } \\
\text { QTc prolongation were noted in } \\
\text { either study. The most common } \\
\text { TEAEs were fatigue, headache, } \\
\text { insomnia, and disturbance in } \\
\text { attention. PK parameters were } \\
\text { stable, predictable, and provide } \\
\text { low peak-to-trough variability on a } \\
\text { once-daily dosing regimen. A } \\
\text { steady state was achieved in } 8 \\
\text { days. }\end{array}$ & $\begin{array}{l}\text { Valbenazine is generally well } \\
\text { tolerated and has predictable PK } \\
\text { parameters that allow for easy } \\
\text { once-daily dosing. }\end{array}$ \\
\hline
\end{tabular}




\section{REFERENCES}

1. Frei K, Truong DD, Fahn S, Jankovic J, Hauser RA. The nosology of tardive syndromes. Journal of the Neurological Sciences. 2018;389:10-16. doi:10.1016/j.j ns.2018.02.008

2. Savitt D, Jankovic J. Tardive syndromes. Journal of the Neurological Sciences. 2018;389:35-42. doi:10.101 6/j.jns.2018.02.005

3. McEvoy J, Gandhi SK, Rizio AA, et al. Effect of tardive dyskinesia on quality of life in patients with bipolar disorder, major depressive disorder, and schizophrenia. Quality of Life Research. 2019;28(12):3303-3312. doi:10.1007/s11136-019-022 $\underline{69-8}$

4. Medication-Induced Movement Disorders and Other Adverse Effects of Medication. In: Diagnostic and Statistical Manual of Mental Disorders. 5th ed. American Psychiatric Association; 2013.

5. Hauser RA, Truong D. Tardive dyskinesia: Out of the shadows. Journal of the Neurological Sciences. 2018;389:1-3. doi:10.1016/j.jns.2018.02.009

6. Carbon M, Hsieh CH, Kane JM, Correll CU. Tardive Dyskinesia Prevalence in the Period of SecondGeneration Antipsychotic Use. The Journal of Clinical Psychiatry. 2017;78(3):e264-e278. doi:10.4088/ICP.16r $\underline{10832}$

7. D’Abreu A, Akbar U, Friedman JH. Tardive dyskinesia: Epidemiology. Journal of the Neurological Sciences. 2018;389:17-20. doi:10.1016/j.jns.2018.02.0 $\underline{07}$

8. Cornett EM, Novitch M, Kaye AD, Kata V, Kaye AM. Medication-Induced Tardive Dyskinesia: A Review and Update. The Ochsner journal. 2017;17(2):162-174.

9. Scorr LM, Factor SA. VMAT2 inhibitors for the treatment of tardive dyskinesia. Journal of the Neurological Sciences. 2018;389:43-47. doi:10.1016/j.j $\underline{\text { ns.2018.02.006 }}$

10. Citrome L. Clinical management of tardive dyskinesia: Five steps to success. Journal of the Neurological Sciences. 2017;383:199-204. doi:10.1016/ j.jns.2017.11.019

11. Correll CU, Schenk EM. Tardive dyskinesia and new antipsychotics. Current Opinion in Psychiatry. 2008;21(2):151-156. doi:10.1097/YCO.0b013e3282f53 132
12. Frei K. Tardive dyskinesia: Who gets it and why. Parkinsonism and Related Disorders. 2019;59:151-154. doi:10.1016/i.parkreldis.2018.11.017

13. Stahl SM. Neuronal traffic signals in tardive dyskinesia: not enough "stop" in the motor striatum. CNS Spectrums. 2017;22(6):427-434. doi:10.1017/S109 285291700061X

14. Ward KM, Citrome L. Antipsychotic-Related Movement Disorders: Drug-Induced Parkinsonism vs. Tardive Dyskinesia-Key Differences in Pathophysiology and Clinical Management. Neurology and Therapy. 2018;7(2):233-248. doi:10.1007/s4012 0-018-0105-0

15. Mahmoudi S, Lévesque D, Blanchet PJ. Upregulation of dopamine D3, not D2, receptors correlates with tardive dyskinesia in a primate model. Movement Disorders. 2014;29(9):1125-1133. doi:10.10 02/mds.25909

16. Lévesque C, Hernandez G, Mahmoudi S, et al. Deficient striatal adaptation in aminergic and glutamatergic neurotransmission is associated with tardive dyskinesia in non-human primates exposed to antipsychotic drugs. Neuroscience. 2017;361:43-57. do i:10.1016/i.neuroscience.2017.07.068

17. Solmi M, Pigato G, Kane JM, Correll CU. Clinical risk factors for the development of tardive dyskinesia. Journal of the Neurological Sciences. 2018;389:21-27. $\underline{\mathrm{d}}$ oi:10.1016/i.jns.2018.02.012

18. Vancampfort D, Correll CU, Galling B, et al. Diabetes mellitus in people with schizophrenia, bipolar disorder and major depressive disorder: A systematic review and large scale meta-analysis. World Psychiatry. 2016;15(2):166-174. doi:10.1002/wp s.20309

19. Jain R, Correll CU. Tardive Dyskinesia: Recognition, Patient Assessment, and Differential Diagnosis. The Journal of Clinical Psychiatry. 2018;79(2):16-23. doi:10.4088/JCP.nu17034ah1c

20. Margolius A, Fernandez HH. Current treatment of tardive dyskinesia. Parkinsonism and Related Disorders. 2019;59:155-160. doi:10.1016/i.parkreldi s.2018.12.022

21. Peselow ED, Angrist BM, Rotrosen J. Changes in tardive dyskinesia after fluphenazine decanoate discontinuation. Annals of Clinical Psychiatry. 1989;1(3):187-191. doi:10.3109/10401238909149978 
22. Bhidayasiri R, Fahn S, Weiner WJ, Gronseth GS, Sullivan KL, Zesiewicz TA. Evidence-based guideline: Treatment of tardive syndromes: Report of the Guideline Development Subcommittee of the American Academy of Neurology. Neurology. 2013;81(5):463-469. doi:10.1212/WNL.0b013e31829d $\underline{86 \mathrm{~b} 6}$

23. Shenoy RS, Sadler AG, Goldberg SC, Hamer RM, Ross B. Effects of a six-week drug holiday on symptom status, relapse, and tardive dyskinesia in chronic schizophrenics. Journal of Clinical Psychopharmacology. 1981;1(3):141-145. doi:10.1097/ 00004714-198105000-00005

24. Waln O, Jankovic J. An Update on Tardive Dyskinesia: From Phenomenology to Treatment. Tremor and Other Hyperkinetic Movements. 2013;3(0):03. doi:10.5334/tohm.165

25. Emsley R, Ch MBB, Med M, Psych FCJ, Turner MB. A Single-Blind, Randomized Trial Comparing Quetiapine and Haloperidol in the Treatment of Tardive Dyskinesia. Vol 65. Physicians Postgraduate Press, Inc.; 2004.

26. Chan HY, Chiang SC, Chang CJ, et al. A Randomized Controlled Trial of Risperidone and Olanzapine for Schizophrenic Patients With Neuroleptic-Induced Tardive Dyskinesia. The Journal of Clinical Psychiatry. 2010;71(09):1226-1233. doi:10.4 088/ICP.09m05155yel

27. Simpson GM, Lee JH, Shrivastava RK. Clozapine in tardive dyskinesia. Psychopharmacology. 1978;56(1):75-80. doi:10.1007/BF00571412

28. Bhidayasiri R, Jitkritsadakul O, Friedman JH, Fahn S. Updating the recommendations for treatment of tardive syndromes: A systematic review of new evidence and practical treatment algorithm. Journal of the Neurological Sciences. 2018;389:67-75. doi:10.101 6/i.jns.2018.02.010

29. Angus S, Sugars J, Boltezar R, Koskewich S, Schneider NM. A controlled trial of amantadine hydrochloride and neuroleptics in the treatment of tardive dyskinesia. Journal of Clinical Psychopharmacology. 1997;17(2):88-91. doi:10.1097/0 0004714-199704000-00004

30. Albin RL, Young AB, Penney JB. The functional anatomy of basal ganglia disorders. Trends in Neurosciences. 1989;12(10):366-375. doi:10.1016/016 6-2236(89)90074-X

31. Pappa S, Tsouli S, Apostolou G, Mavreas V, Konitsiotis S. Effects of amantadine on tardive dyskinesia: A randomized, double-blind, placebocontrolled study. Clinical Neuropharmacology. 2010;33(6):271-275. doi:10.1097/WNF.0b013e3181ffd $\underline{\mathrm{e} 32}$
32. Thaker GK, Nguyen JA, Strauss ME, Jacobson R, Kaup BA, Tamminga CA. Clonazepam treatment of tardive dyskinesia: A practical GABAmimetic strategy. American Journal of Psychiatry. 1990;147(4):445-451. doi:10.1176/ajp.147.4.445

33. Soares-Weiser K, Fernandez HH. Tardive dyskinesia. Seminars in Neurology. 2007;27(2):159-169. doi:10.1055/s-2007-971169

34. Adler LA, Peselow E, Rotrosen J, et al. Vitamin E treatment of tardive dyskinesia. In: American Journal of Psychiatry. Vol 150. ; 1993:1405-1407. doi:10.1176/a jp.150.9.1405

35. Adler LA, Rotrosen J, Edson R, et al. Vitamin E treatment for tardive dyskinesia. Archives of General Psychiatry. 1999;56(9):836-841. doi:10.1001/archpsy c.56.9.836

36. Zhang WF, Tan YL, Zhang XY, Chan RCK, Wu HR, Zhou DF. Extract of Ginkgo biloba Treatment for Tardive Dyskinesia in Schizophrenia. The Journal of Clinical Psychiatry. 2011;72(05):615-621. doi:10.4088/ ICP.09m05125yel

37. van Harten PN, Hovestadt A. Botulinum toxin as a treatment for tardive dyskinesia. Movement Disorders. 2006;21(8):1276-1277. doi:10.1002/mds.20904

38. Rapaport A, Sadeh M, Stein D, et al. Botulinum toxin for the treatment of oro-facial-lingualmasticatory tardive dyskinesia. Movement Disorders. 2000;15(2):352-355. doi:10.1002/1531-8257(200003)1 5:23.0.CO;2-X

39. Peng LY, Lee Y, Lin PY. Electroconvulsive therapy for a patient with persistent tardive dyskinesia: A case report and literature review. Journal of ECT. 2013;29(3). doi:10.1097/YCT.0b013e31829e0aea

40. Yasui-Furukori N, Nakamura K, Katagai H, Kaneko $\mathrm{S}$. The effects of electroconvulsive therapy on tardive dystonia or dyskinesia induced by psychotropic medication: a retrospective study. Neuropsychiatric Disease and Treatment. 2014;10:1209. doi:10.2147/ND T.S62490

41. Kefalopoulou Z, Paschali A, Markaki E, Vassilakos P, Ellul J, Constantoyannis C. A double-blind study on a patient with tardive dyskinesia treated with pallidal deep brain stimulation. Acta Neurologica Scandinavica. 2009;119(4):269-273. doi:10.1111/j.160 0-0404.2008.01115.x

42. Schrader C, Peschel T, Petermeyer M, Dengler R, Hellwig D. Unilateral deep brain stimulation of the internal globus pallidus alleviates tardive dyskinesia. Movement Disorders. 2004;19(5):583-585. doi:10.100 2/mds. 10705 
43. Pouclet-Courtemanche H, Rouaud T, Thobois S, et al. Long-term efficacy and tolerability of bilateral pallidal stimulation to treat tardive dyskinesia. Neurology. 2016;86(7):651-659. doi:10.1212/WNL.000 0000000002370

44. Damier P, Thobois S, Witjas T, et al. Bilateral deep brain stimulation of the globus pallidus to treat tardive dyskinesia. Archives of General Psychiatry. 2007;64(2):170-176. doi:10.1001/archpsyc.64.2.170

45. Deng ZD, Li D, Zhang C, Pan YX, Zhang J, Jin H. Long-term follow-up of bilateral subthalamic deep brain stimulation for refractory tardive dystonia. Parkinsonism \& related. Published online 2017.

46. Shaikh AG, Mewes K, DeLong MR, Gross RE. Temporal profile of improvement of tardive dystonia after globus pallidus deep brain stimulation.

Parkinsonism \& related. Published online 2015.

47. Ondo WG, Hanna PA, Jankovic J. Tetrabenazine treatment for tardive dyskinesia: Assessment by randomized videotape protocol. American Journal of Psychiatry. 1999;156(8):1279-1281. doi:10.1176/ajp.1 $\underline{56.8 .1279}$

48. Leung JG, Breden EL. Tetrabenazine for the treatment of tardive dyskinesia. The Annals of pharmacotherapy. 2011;45(4):525-531. doi:10.1345/ap $\underline{\text { h.1P312 }}$

49. Stamler D, Bradbury M, Brown F. The pharmacokinetics and safety of deuteratedtetrabenazine (P07. 210). Published online 2013.

50. Fernandez HH, Factor SA, Hauser RA, et al. Randomized controlled trial of deutetrabenazine for tardive dyskinesia the ARM-TD study. Neurology. 2017;88(21):2003-2010. doi:10.1212/WNL.000000000 $\underline{0003960}$

51. Anderson KE, Stamler D, Davis MD, et al. Deutetrabenazine for treatment of involuntary movements in patients with tardive dyskinesia (AIMTD): a double-blind, randomised, placebo-controlled, phase 3 trial. The Lancet Psychiatry.

2017;4(8):595-604. doi:10.1016/S2215-0366(17)3023 $\underline{6-5}$

52. Uhlyar S, Rey JA. Valbenazine (Ingrezza): The first FDA-approved treatment for tardive dyskinesia. $P$ and T. 2018;43(6):328-331.

53. Jankovic J. Dopamine depleters in the treatment of hyperkinetic movement disorders. Expert Opinion on Pharmacotherapy. 2016;17(18):2461-2470. doi:10.1 080/14656566.2016.1258063
54. Müller T. Valbenazine granted breakthrough drug status for treating tardive dyskinesia. Expert Opinion on Investigational Drugs. 2015;24(6):737-742. doi:10.1 517/13543784.2015.1029573

55. O’Brien CF, Jimenez R, Hauser RA, et al. NBI-98854, a selective monoamine transport inhibitor for the treatment of tardive dyskinesia: A randomized, double-blind, placebo-controlled study. Movement Disorders. 2015;30(12):1681-1687. doi:10.1 $\underline{002 / \text { mds. } 26330}$

56. Hauser RA, Factor SA, Marder SR, et al. KINECT 3: A phase 3 randomized, double-blind, placebocontrolled trial of valbenazine for tardive dyskinesia. American Journal of Psychiatry. 2017;174(5):476-484. $\underline{\mathrm{d}}$ oi:10.1176/appi.aip.2017.16091037

\section{FDA. Valbenazine Drug Information.}

58. Grigoriadis DE, Smith E, Hoare SRJ, Madan A, Bozigian H. Pharmacologic characterization of valbenazine (NBI-98854) and its metabolites. Journal of Pharmacology and Experimental Therapeutics. 2017;361(3):454-461. doi:10.1124/jpet.116.239160

59. Stahl SM. Comparing pharmacologic mechanism of action for the vesicular monoamine transporter 2 (VMAT2) inhibitors valbenazine and deutetrabenazine in treating tardive dyskinesia: does one have advantages over the other? Published online 2018. doi:10.1017/S1092852918001219

60. Stahl SM. Dazzled by the dominions of dopamine: Clinical roles of D3, D2, and D1 receptors. CNS Spectrums. 2017;22(4):305-311. doi:10.1017/S1092852 $\underline{917000426}$

61. Huang M, He W, Rajagopal L, Kudwa A, Grigoriadis DE, Meltzer HY. Effects of NBI-98782, a selective vesicular monoamine transporter 2 (VMAT2) inhibitor, on neurotransmitter efflux and phencyclidine-induced locomotor activity: Relevance to tardive dyskinesia and antipsychotic action. Pharmacology Biochemistry and Behavior. 2020;190:172872. doi:10.1016/i.pbb.2020.172872

62. Stahl SM. Neuronal traffic signals in tardive dyskinesia: Not enough stop in the motor striatum. CNS Spectrums. 2017;22(6):427-434. doi:10.1017/S109 $285291700061 \mathrm{X}$

63. Luo R, Bozigian H, Jimenez R, Loewen G, O’Brien $\mathrm{CF}$. Single dose and repeat once-daily dose safety, tolerability and pharmacokinetics of valbenazine in healthy male subjects. Psychopharmacology Bulletin. 2017;47(3):44-52. 
64. Stahl SM. Mechanism of action of vesicular monoamine transporter 2 (VMAT2) inhibitors in tardive dyskinesia: reducing dopamine leads to less "go" and more "stop" from the motor striatum for robust therapeutic effects. Published online 2017. do i:10.1017/S1092852917000621

65. Caroff SN, Campbell EC. Drug-Induced Extrapyramidal Syndromes: Implications for Contemporary Practice. Psychiatric Clinics of North America. 2016;39(3):391-411. doi:10.1016/i.psc.201 $\underline{6.04 .003}$

66. Neurocrine Biosciences. Highlights of prescribing information. INGREZZA (valbenazine) capsules, for oral use. Published online 2017.

67. Thai-Cuarto D, O’Brien CF, Jimenez R, Liang GS, Burke J. Cardiovascular Profile of Valbenazine: Analysis of Pooled Data from Three Randomized, Double-Blind, Placebo-Controlled Trials. Drug Safety. 2018;41(4):429-440. doi:10.1007/s40264-017-0623-1
68. Solmi M, Pigato G, Kane JM, Correll CU. Treatment of tardive dyskinesia with VMAT-2 inhibitors: A systematic review and meta-analysis of randomized controlled trials. Drug Design, Development and Therapy. 2018;12:1215-1238. doi:1 0.2147/DDDT.S133205

69. Factor SA, Remington G, Comella CL, et al. The Effects of Valbenazine in Participants with Tardive Dyskinesia: Results of the 1-year KINECT 3 Extension Study. Journal of Clinical Psychiatry.

2017;78:9(November/December):1344-1350. doi:10.4 088/ICP. $17 \mathrm{~m} 11777$

70. Correll CU, Josiassen RC, Liang GS, Burke J, O'Brien CF. Efficacy of valbenazine (NBI-98854) in treating subjects with tardive dyskinesia and schizophrenia or schizoaffective disorder. Psychopharmacology Bulletin. 2017;47(3):69-76.

71. Citrome L. Valbenazine for tardive dyskinesia: A systematic review of the efficacy and safety profile for this newly approved novel medication-What is the number needed to treat, number needed to harm and likelihood to be helped or harmed? International Journal of Clinical Practice. 2017;71(7):1-14. doi:10.11 11/ijcp.12964 